\title{
Research on the International Strategy for National Cyberspace Security
}

\author{
Fang Binxing ${ }^{1}$, Du Aning ${ }^{2}$, Zhang $\mathrm{Xi}^{3}$, Wang Zhongru ${ }^{3}$ \\ 1. Cyber Security Association of China, Beijing 100010, China \\ 2. Office of the Central Leading Group for Cyberspace Affairs, Beijing 100010, China \\ 3. Beijing University of Posts and Telecommunications, Beijing 100876, China
}

\begin{abstract}
Cyberspace security has been a crucial part in national security and is more and more important role in the development of economy and society. Based on the current situation of international cyberspace security, this article analyzes the opportunities and challenges that China is confronted with, and studies China's international cyberspace security strategy suitable for its own values and national interests. We then propose the objectives, principles, and tasks of the strategy.
\end{abstract}

Keywords: cyberspace security; cyberspace governance; cyberspace strategy

\section{Introduction}

Cyberspace is regarded as the fifth domain, after land, sea, air, and space. It has become a major battlefield, where powerful governments try to strengthen their control and use of cyberspace. By August 2015, 64 countries around the world had developed their national cyberspace security strategy [1,2], and the US and Russia had introduced international cyberspace security strategies. In 2013, the European Union prepared its own cyberspace security strategy as an organization of nations [3]. Generally speaking, almost every major power around the globe, with the exception of China, has developed its national cyberspace security strategy. Therefore, China has an urgent need to learn from the experiences of other countries and develop its own cyberspace security strategy, one that is suitable for China's values and national interests.

\section{Objectives and principles of international strategy for cyberspace security}

Based on the current development stage and tasks of cyberspace in China, the international strategy for cyberspace security should comply with the following objectives and principles.

\subsection{Strategic objectives}

Starting with the safeguarding of China's national cyberspace sovereignty, and followed by the construction of effective cyberspace regulation, China should urge the international community to build a peaceful, secure, open, and cooperative cyberspace that is based on mutual respect and trust. The final goal will be the construction of a multilateral, democratic, and transparent international governance system for the Internet.

\subsection{Strategic principles}

\subsubsection{Respect cyberspace sovereignty}

The principles of sovereign equality that are enshrined in the Charter of the United Nations cover various aspects of international communications. These principles are the basic criteria of modern international relations, and should also apply to cyberspace. Applied to cyberspace, these principles include: respecting the right of all countries to choose their own development path, management methods, and public policy strategy; allowing

Received date: 12 October 2016; revised date: 21 October 2016

Corresponding author: Fang Binxing, Chinese Academy of Engineering, Academician. Major research field is cyberspace security. E-mail: fangbx@bupt.edu.cn Funding program: CAE Major Advisory Project "Research on Cyberspace Security Strategy" (2015-ZD-10)

Chinese version: Strategic Study of CAE 2016, 18 (6): 013-016

Cited item: Fang Binxing et al. Research on the International Strategy for National Cyberspace Security. Strategic Study of CAE, http://10.15302/J-SSCAE-2016.06.003 
equal participation in the international governance of cyberspace; not engaging in cyberspace hegemony; not interfering with the internal affairs of other countries; and not undertaking, conniving at, or supporting cyber activities that jeopardize the national security of other countries.

\subsubsection{Maintain peace and security}

Cyberspace should not become the battlefield of nations, nor should it become a hotbed of crime. Countries should work together to prevent the use of cyberspace for terrorism, pornography, drug trafficking, money laundering, gambling, and other criminal activities. Illegal attacks - ranging from stealing information to hacking government networks - should be resolutely cracked down upon, according to relevant laws and international conventions.

\subsubsection{Promote openness and cooperation}

To enhance the governance system of the global Internet and to maintain the regulation of cyberspace, China must adhere to the principles of mutual trust and mutual benefit, and abandon old concepts such as zero-sum game and "winner takes all." Countries should promote openness and cooperation in the Internet, enrich the breadth and depth of openness, build more platforms for communication and cooperation, and create more common points of interest, cooperation, and mutual benefit. In this way, complementary advantages can be achieved, allowing more countries and people to share in the benefits of Internet development in the current information era.

\subsubsection{Construct cyberspace regulation}

Cyberspace is an analogy of the real world; thus, freedom must be provided in cyberspace, and order must be maintained. Although cyberspace itself exists in a virtual world, the building blocks of cyberspace are real; therefore, laws, rights, and obligations must be clarified and complied with. At the same time, China must strengthen the construction of ethics and encourage civilized behavior in cyberspace, in order to enable moral education to provide a guiding role in the development and use of cyberspace. In this way, the cyberspace environment will be repaired and nourished by the strength of human progress.

\section{Strategic tasks of international strategy for cyberspace security}

China contains the largest number of Internet users and the greatest network size in the world. Thus, it is of extreme importance both to China itself and to the world to maintain good security in Chinese cyberspace, as well as in international cyberspace. China is committed to safeguarding its national interests of cyberspace sovereignty, security, and development, and to promoting the peaceful use and co-governance of cyberspace for the benefit of humanity.

\subsection{Clearly advocate for cyberspace sovereignty}

Actively promote cyberspace sovereignty: Every country's right to independently choose its own cyberspace development path, select its cyberspace management mode, develop its public policy concerning the Internet, and participate equally in in ternational cyberspace governance should be respected. As the main advocator of cyberspace sovereignty, China should systematically expound the implications and breadth of this concept. The introduction of a cyberspace sovereignty white paper, and its acceptance as the consensus and common code of conduct of the international community, will construct a new international cyberspace governance system.

Enhance hard power in maintaining cyberspace sovereignty: To protect the normal exercise of cyberspace sovereignty, including the rights of independence, equality, self-defense, and jurisdiction, China must draw from other aspects, including technology, law, diplomacy, and the military. Hard power is necessary, especially in the field of information, in order to protect China's cyberspace from outside interference, attack, and detonation and to protect the independence of the national network service. Therefore, a safe and controllable domain-name resolution plan and an international cooperation mechanism should be proposed in order to safeguard cyberspace sovereignty.

Improve and respect international cyberspace sovereignty cooperation: First, in order to construct a real basis for international cooperation, cyberspace sovereignty and the key interests of each country must be respected. Thus, China must cultivate a cyberspace consensus and constantly expand international interest in cyberspace cooperation. Next, in order to establish a multilateral, democratic, and transparent international cyberspace governance system, China must strengthen the communication on technology, institutional design, and management capabilities of the international community, and work together to build the multilateral, democratic, transparent international governance system for the Internet.

\subsection{Advocate for the peaceful use of cyberspace}

Advocate for the peaceful use of the Internet: China opposes the militarization of cyberspace and the use of information and communication technology (ICT) to interfere in the internal affairs of other countries or to undermine their political, economic, and social stability.

Promote the development of laws that are applicable to armed conflict in cyberspace: Because of the special features of cyberspace, the United Nation's Law of Armed Conflict cannot be directly applied to it. Therefore, China need to modify this law to ensure that it includes and is relevant to the characteristics of cyberspace. Furthermore, methods and principles for identifying the sources of cyberspace attacks and losses must be clarified.

Encourage innovation in and peaceful application of network 
technology: China must encourage the use of ICT to promote social and economic development, human wellbeing, and the peace, security, and stability of the international community. Furthermore, China should promote the construction of a cyberspace infrastructure that permits active use, scientific development, and management by law.

\subsection{Build a secure and trusted cyberspace}

Implement cybersecurity censorship: The cybersecurity censorship is required to ensure the security of information technology products and the service supply chain; promote the application of independent and controllable information technology products in China's key information infrastructures; and prevent other countries from utilizing their own resources, key facilities, core technologies, ICT products and services, information and communication networks, and other advantages to undermine China's independent control of ICT products and services, or to threaten China's political, economic, and social security.

Promote an electronic identity authentication system: China should support the R\&D of secure and convenient electronic cyberspace identity authentication technology, and accelerate the reconciliation of different technologies. Furthermore, China should actively promote the international and mutual recognition of electronic identities.

Combat crime and terrorism in cyberspace: China is against any form of attack or spying in cyberspace. In order to protect the legitimate rights and interests of China's citizens, China should relentlessly crack down on cyber crime, cyber terrorism, cyber attacks, and the infringement of privacy, according to the law. Furthermore, China should establish an international emergency response system and actively respond to all kinds of international Internet security incidents.

\subsection{Promote the development of cyberspace}

Eliminate the international digital divide: In order to enable equal accessibility for everyone, so that everyone can acquire knowledge and information from the network, and in order to create an interconnected information highway to benefit more developing countries, China should support international communities in enhancing their capacity for building the network, popularizing the information infrastructure, and breaking down information barriers.

Promote the innovation and development of cyber economies: Learning from foreign experiences and achievements, China should allow the Internet to play an optimizing and integrating role in allocating production factors, combining networks with traditional industries, and promoting mutual prosperity. China should facilitate constant innovation in information technology, comprehensively popularize the information infrastructure, effectively develop and utilize information resources, and increase the contribution rate of the Internet to national production.

Promote the prosperity and development of a transnational Internet: In order to promote the prosperity and development of a transnational Internet, China should formulate and perfect trade regulations for cyberspace, while acting against protectionism. In addition, China should form a worldwide network market and promote the prosperity and development of an international cyber economy. China should build a platform for online cultural sharing in order to enable the spread of humankind's outstanding cultures, enhance exchanges and mutual learning in Chinese and foreign cultures, carry forward the positive energy of human civilization, and encourage meaningful exchanges among people from all countries.

\subsection{Build a free and orderly cyberspace}

Promote the mutual sharing and governance of cyberspace: In order to promote the mutual governance of cyberspace, China should insist on the principles of mutual respect and mutual trust; formulate international cyberspace regulations that are generally accepted, fair, and reasonable; and build a cooperation mechanism and an exchange platform of cyberspace governance that operates on a regular basis through. China should also deepen communication with other countries and parties, improve mutual trust, resolve conflicts, consolidate consensus, enhance mutual governance, and realize a "win-win" situation.

Construct effective cyberspace order: In order to maintain good order in cyberspace, China should strengthen cyber legislation, specify the powers and responsibilities of law enforcement departments, reinforce the management of harmful information on websites, and crack down on the propagation of illegal information, all according to the law. In order to better regulate the cross-border flow of information, obtain evidence, and enforce the law, China should enhance collaboration with the international community. In addition, China should improve technology and management measures in order to deal with harmful information in a timely manner, and eliminate its influence.

Advocate for civilized behavior in the cyberspace: China should advocate for civilized behavior in cyberspace, reject rumors and frauds, strengthen the protection of minors on the Internet, and crack down on the propagation of pornography, violence, and other harmful information. In addition, China should work toward widely spreading positive energy, inheriting and carrying forward the best of humankind's cultures, producing more cultural high-quality digital goods, and transforming cyberspace into a vibrant spiritual homeland for humankind.

\subsection{Accelerate the construction of a global network infrastructure}

Accelerate the construction of a global network infrastruc- 
ture: In order to play a bigger role in the building of a global network infrastructure, China should encourage and promote the connection of relevant China's enterprises to the "One Belt and One Road" strategy, along with other national strategies. China should assist more countries to improve their broadband, advance their network accessibility and interconnection to cyberspace, and upgrade their network competence, in order to help provide secure and convenient network services for other societies.

China should support the developing countries in enhancing their capacity to build networks, popularize the information infrastructure, and break down information barriers. In addition, China should provide funds and technologies to developing countries to assist the development of their information security capabilities, and to increase their ability to conduct cooperation and joint action. This process will also enable China to promote its international image and improve soft power.

\subsection{Enhance cooperation and communication between technical personnel}

Expand international influence in the field of cyberspace security: China should support a batch of top-ranked scholars, research organizations, and industrial leaders in order to help them positively influence or even lead the development of cyberspace security. In this way, China can enlarge its influence and discourse power in the field of cyberspace security, increase its technological reputation, and improve its industrial brand and national image.

Strengthen international cooperation and cyber security technology sharing: China should strengthen international technological cooperation in telecommunication, mobile Internet, cloud computing, the Internet of things (IoT), big data, and other fields; such cooperation will allow countries to solve technological problems in the Internet together and to jointly formulate strategies and standards. Thus, China can promote the development of new technologies, new industries, and new mechanisms, and apply sophisticated Internet technologies in a broader and more secure way.

Conduct international cybersecurity personnel exchanges: To promote the joint training of top security personnel to deal with the continually evolving innovations in cyberspace, China should support its cyberspace security talents, encourage them to collaborate with relevant international organizations, attract talents from other counties for China's benefit, and build a "talent highland" - that is, a community of high-talent individuals working together. China should also encourage cooperation among countries, regions, social organizations, and individuals through the Internet, thereby solving security challenges together.

\subsection{Build a international governance system of the Internet}

Promote mutual sharing and governance in cyberspace: China should maintain the principles of mutual respect and mutual trust in order to develop international cyberspace regulations that are fair, reasonable, and acceptable to all parties. Moreover, China should deepen communication, improve mutual trust, resolve conflicts, consolidate a consensus, and promote mutual governance with other countries and parties. In this way, China can create a "win-win" situation and continually increase the convergence of interests with those of the international community.

Support the leading role of the United Nations: China should actively support the United Nations (UN) in playing a leading role in maintaining international peace and security in cyberspace areas; facilitate the formulation of a universal and effective national code of conduct in cyberspace, under the UN framework; and support the UN in playing an important role in aspects such as developing international laws and regulations for information security, peacefully resolving cyberspace-related conflicts, and accelerating cooperation between countries.

Advocate participation in international governance on an equal basis: China should encourage international communities to improve the multilateral governance system of the Internet, to strive toward mutual governance and the fair allocation of basic Internet resources, and to safeguard countries' equal right to participate in the governance of the international Internet.

Promote cooperation among international organizations: China should strengthen cooperation within multilateral international frameworks, including the UN, the International Telecommunication Union (ITU), the Shanghai Cooperation Organization (SCO), the economic association of Brazil, Russia, India, China, and South Africa (BRICS), and the ASEAN Regional Forum (ARF) in order to improve the coordination between and joint response of concerned international organizations.

\subsection{Cooperatively deal with cyber crime and cyber terrorism}

Jointly maintain cybersecurity: China should actively strengthen cooperation with the international community in the field of cyberspace security; build channels for exchanges and communications that allow China to face security threats together; build a cooperation mechanism that includes scouting activities, early warning, and law enforcement; improve international cooperation in fields such as computer emergency response; and promote exchanges of experience, along with cooperation in information sharing, personnel exchange, the development of technical equipment, information sharing, and case investigation in infringement cases.

Jointly fight cyber terrorism: China should build a cooperation mechanism for the international network in order to deter terrorism, jointly fight against terrorist activities via the Internet and cut off channels for providing violent and terrorist-related information. China should also jointly crack down on terrorist activities that use ICTs and the information communication network; fight against activities that impair the public infrastructure 
or propagate terrorism, separatism, or extremism; and oppose activities that incite ethnic, racial, or religious hostility.

\section{References}

[1] NATO Cooperative Cyber Defence Centre of Excellence. Cyber security strategy documents [EB/OL]. (2015-08-03) [2016-09-30]. https://ccdcoe.org/strategies-policies.html. Chinese.

[2] International Telecommunication Union. National strategies [EB/ OL]. (2015-08-01) [2016-09-15]. https://www.itu.int/en/ITU-D/ Cybersecurity/Pages/National-Strategies.aspx. Chinese.

[3] Li Y X, Xie Y J. Analysis and enlightenment on the cybersecurity strategy of various countries in the world [J]. Chinese Journal of Network and Information Security, 2016, 2 (1):1-5. Chinese. 